\title{
Prolegómenos sobre o processo de transformação capitalista da actividade educativa nos níveis básico e secundário de escolaridade
}

\author{
Leopoldo Mesquita \\ Universidade do Porto, Portugal
}

\begin{abstract}
Resumo
Pretende-se neste texto apresentar os fundamentos do que se considera ser um novo campo de investigação educativa, cujo objecto é a transformação capitalista (ou capitalização) da actividade educativa nos níveis básico e secundário de escolaridade, aqui considerada como sendo a tendência actualmente dominante nas políticas educativas a nível global. Argumenta-se que uma tal mudança educativa configura um processo clássico de transição capitalista cujo ponto nodal reside na transformação do trabalho escolar. Sob o lema da "melhoria contínua" dos resultados escolares, pretende-se que a produtividade do trabalho do professor seja aferida pela produtividade do trabalho do aluno. Impõe-se neste contexto um estudo detalhado das formas de valorização dos capitais investidos na indústria educativa. Decorrendo sobretudo no interior dos sistemas públicos de educação, a presente mudança educativa envolve mudanças profundas nas estruturas estatais e nas relações de produção educativa, para a análise das quais se utilizam os conceitos operativos de Estado capitalizador e de formas pró-capitalistas de mercado.
\end{abstract}

Palavras-chave

Capitalização dos sistemas educativos; Trabalho escolar; Estado capitalizador da actividade educativa

\section{Introdução}

A tese geral que aqui se defende é a de que está actualmente em curso nos sistemas educativos e na actividade educativa a nível mundial e 
global uma transformação capitalista com um ritmo, uma amplitude e uma profundidade comparáveis às revoluções que ocorreram, sobretudo a partir dos séculos XVII/XVIII, na produção industrial e nos serviços (Mesquita, 2009b, pp. 9-105).

$\mathrm{Na}$ sua fase actual, o processo de capitalização da actividade educativa é marcado por um protagonismo crescente das classes empresariais e das suas organizações nas principais iniciativas e movimentos de inovação e de reforma, e bem assim pelo surgimento e expansão de novas e poderosas empresas educativas de natureza privada e com fins lucrativos, as quais vão progressivamente penetrando e dominando todas as áreas da actividade escolar, desde as instalações e infra-estruturas até à gestão global de escolas e sistemas escolares, passando pela administração do currículo e da avaliação das aprendizagens, pela contratação, formação e avaliação dos professores e educadores, etc. Embora a mudança educativa assim perspectivada tenha já hoje adquirido características de um fenómeno de dimensão global, é nos países avançados do chamado mundo anglo-saxónico que a mesma assume um carácter mais desenvolvido e de contornos mais definidos, razão pela qual privilegiaremos no presente estudo a situação nesses países, designadamente nos Estados Unidos da América.

Neste país, em 1992, Christopher Whittle protagonizou, com The Edison Project, a primeira experiência actual de criação de uma empresa com fins lucrativos para gerir escolas dos sistemas públicos de educação, a que logo se seguiram outras (Saltman, 2005) ${ }^{1}$. Alguns anos mais tarde G. Hentschke podia afirmar que "uma 'indústria educativa' completa ganhou proeminência" (Hentschke, 2006, 14) e Patrícia Burch destacava "o crescente mercado de produtos e serviços educativos impulsionado pelos mandatos federais e locais de avaliação de resultados" (Burch, 2006, p. 2589)2. Mais recentemente, Alex Molnar e colegas referiam que, entre 1998 e 2010, o número de Educational Management Organizations (EMOs) com fins lucrativos nos EUA tinha aumentado de 14 para 98 e o número de escolas geridas por essas EMOs tinha subido de 131 para 729 (Molnar et al, pp. 4-6). O optimismo actual dos defensores do capitalismo educacional é por sua vez expresso por M. Sandler nos seguintes termos: "Estes são tempos favoráveis para os empresários da indústria educativa. O governo, os capitalistas e os filantropos estão concentrados no empreendedorismo social e na educação como grandes prioridades" (Sandler, 2010, p. 141). 
Tendo como palco privilegiado os sistemas públicos de educação, o dito processo de capitalização envolve uma transformação profunda no trabalho que é desenvolvido no meio escolar, assim como nas estruturas estatais que acolhem, organizam e dirigem a actividade educativa. No quadro do que designamos como Estado capitalizador e formas pró-capitalistas de mercado por este promovidas na actividade educativa, o objectivo de "melhoria contínua" dos resultados escolares impulsiona uma transformação de tipo capitalista nas relações sociais de produção educativa e institui a produtividade do aluno como tema central no presente processo de mudança. Neste contexto, reveste-se de uma particular importância o estudo das formas de valorização dos capitais investidos na indústria educativa.

A explanação dos fundamentos da actual transformação educativa a que a seguir se procede será assim dividida em três partes. Na primeira, defende-se que a presente transformação educativa configura um processo clássico de transição capitalista, através do qual se pretendem realizar as funções sociais atribuídas aos sistemas educativos através da instituição de um novo modo de produção educativa. Na segunda, procuramos, com base na teoria marxista, situar o referido processo de capitalização na evolução histórica do modo de produção capitalista, sendo debatidas as condições de valorização do capital na indústria educativa. Finalmente, na terceira parte abordar-se-á o tema da transformação das estruturas estatais responsáveis pela educação de massas e das relações sociais de produção educativa.

O âmbito deste estudo são os sistemas de educação não superior e nele se procura explicitar o sentido principal da presente mudança educativa. Não é pois nosso propósito analisar e aferir o desempenho desses sistemas como resultado das actuais políticas educativas. De igual modo, não cuidamos aqui de analisar os inevitáveis movimentos de resistência a tais políticas e os seus efeitos, quer na criação de obstáculos ao avanço do processo de capitalização quer na formulação de alternativas ao mesmo. Estes são temas da máxima importância cujo tratamento permite estudar com um fundamento reforçado a situação presente e as perspectivas futuras da educação em cada contexto particular e também num plano global. Privilegiamos contudo neste artigo a caracterização da lógica que está na base das actuais transformações nos sistemas públicos de educação. 


\section{Um processo clássico de transição capitalista centrado no aumento da produtividade do trabalho do aluno}

Analisando a realidade da educação pública nos Estados Unidos da América, Mosher, Fuhrman e Cohen afirmam que "no último meio século assistiu-se a uma transformação histórica nos objectivos educativos", transformação essa que definem da seguinte maneira: "o foco transferiu-se dos recursos (...) para a questão de saber se virtualmente todos os estudantes atingem a proficiência nos conhecimentos e nas aptidões fundamentais" (Mosher, Fuhrman e Cohen, 2007). A versão radical da mudança referida por estes autores é a que se contém hoje na expressão "não admitir desculpas", cujo significado é o de que as desigualdades sociais e a quantidade de recursos disponíveis nas escolas são variáveis pouco importantes relativamente ao objectivo de assegurar um pleno "sucesso" educativo de todos os alunos (ver, por exemplo, Thernstrom e Thernstrom, 2004). É esta a tese que se tem vindo a impor nas políticas públicas de educação, não apenas nos EUA mas também em termos praticamente globais e universais.

Sustenta-se neste artigo que um elemento crucial na mudança antes referida reside na procura de aumentar continuamente a produtividade do trabalho escolar (o desígnio de "melhoria contínua" dos resultados escolares) e que uma tal procura envolve uma lógica de "produção educativa" que tem fortes semelhanças com a que existe nos demais sectores produtivos. Em termos históricos recentes, o projecto de capitalização dos sistemas públicos de educação que assim se configura foi explicitamente delineado num texto de Milton Friedman, divulgado pela primeira vez em 1955 (Friedman, 2002). Entretanto, numa obra comemorativa do quinquagésimo aniversário sobre a publicação do mencionado texto, um grupo de autores fez questão de defender que no período de meio século transcorrido desde então se vem assistindo, nos EUA, ao crescimento notório de uma "indústria educativa competitiva", nos termos utilizados pelo próprio M. Friedman (Enlow e Ealy, 2006). A transição para um regime de capitalismo educacional nos sistemas públicos de escolarização de massas está hoje abundantemente documentada em múltiplos estudos e investigações (ver, por exemplo, Hentschke e outros, 2002; Hentschke, 2006; Burch, 2006; Molnar, 2006; McGuinn, 2006; Robertson, 2007; Sandler, 2010), parecendo ser coincidente, 
no seu conteúdo e no seu significado, com a "transformação histórica" que Mosher, Fuhram e Cohen identificaram, nos termos antes referidos.

Defendemos assim que, salvaguardando as fortes especificidades da actual mudança educativa, a mesma configura um processo clássico de transição capitalista. A existência de tal processo representa, para as classes dominantes que o promovem, o propósito de realizar as funções sociais atribuídas aos sistemas educativos através da capitalização desses sistemas. Pretende-se assim articular num mesmo quadro organizativo duas finalidades distintas cometidas aos sistemas de escolarização de massas, a saber, a de meio de formação de trabalhadores e de cidadãos aptos a ocuparem um lugar mais ou menos prescrito na sociedade e no aparelho produtivo, por um lado, e a de fonte de valorização dos capitais investidos na indústria educativa, por outro (Mesquita, 2009a, 2009b).

A escolarização de massas promovida pelo Estado deixa assim de poder ser considerada apenas como um processo diferido da produção e acumulação capitalistas, através da formação da respectiva força de trabalho e da posterior extracção de mais-valia do seu trabalho futuro. Com efeito, na nova organização educativa que agora se configura tenderão a implantar-se processos de valorização capitalista no próprio processo de "produção educativa" e na realização mais ou menos imediata do valor dessa produção. A investigação sobre as actuais mudanças nos sistemas educativos deve assim privilegiar as transformações que se verificam no trabalho escolar, visando constitui-lo em trabalho produtor de mais-valia. E aqui importa não circunscrever essa investigação ao trabalho do professor e colocar antes o foco principal no trabalho do aluno, já que, no contexto do actual processo de capitalização, se pretende que o trabalho do professor seja tanto mais produtivo quanto melhor for capaz de promover e suportar um aumento da produtividade do trabalho do aluno ${ }^{3}$. Na actualidade, uma reestruturação do trabalho escolar com estas características é claramente preconizada pelos promotores do capitalismo educacional (Subotnik e Walberg, 2006; Whittle, 2005, pp. 95-153) e vem registando avanços importantes no âmbito de processos de inovação que assentam no chamado e-learning ou blended learning, pretendendo-se com os mesmos um reforço significativo do trabalho independente e cooperativo dos alunos (cf. Christensen, Horn e Johnson, 2008; Wicks, 2010; Horn e Staker, 2011). 
$\mathrm{Na}$ definição de um quadro analítico para investigar a presente transformação educativa, importa igualmente considerar duas outras características da mesma. A primeira, diz respeito à notável continuidade nas políticas educativas que se tem verificado nas últimas décadas ao nível dos diversos países, independentemente da cor política dos governos em funções. A segunda, refere-se à semelhança, nos princípios e nos métodos, entre a maior parte do que é hoje apresentado como inovações na escolarização de massas e outros movimentos de inovação e mudança que, em épocas históricas distantes, foram já defendidos ou promovidos. As duas questões atrás referidas colocam fortes reservas à atribuição da presente mudança educativa a causas de natureza meramente ideológica e cultural ou apenas relacionadas com alterações recentes nos sistemas gerais de governação e de produção económica. Estas causas e alterações recentes têm a sua importância própria e explicam uma parte das características das actuais transformações nos sistemas públicos de educação. Mas uma compreensão global destas últimas exige a nosso ver que, para além de um ciclo "curto" de mudança educativa (que, nos termos antes referidos, respeita aproximadamente ao último meio século), se considere igualmente um ciclo "longo" de mudança educativa, cujas raízes e fundamentos residem na própria natureza e lógica do capitalismo industrial moderno e cujo horizonte histórico é mais ou menos coincidente com o deste último. Isto significa que, no estudo das actuais transformações na educação, se valorizem as afinidades que nelas é possível observar relativamente aos processos gerais que conduziram à instituição do modo de produção capitalista nos demais sectores produtivos. E significa igualmente procurar na história secular da relação entre o capitalismo e a escolarização de massas outras experiências que possam servir de termo de comparação com a situação presente.

Assim, é possível encontrar antecedentes importantes da presente transformação educativa num passado muito mais longínquo do que o horizonte temporal das últimas décadas. Não há diferenças significativas, por exemplo, entre os princípios do capitalismo educacional actual e aqueles que presidiram à acção das escolas monitoriais de Joseph Lancaster ou ao projecto da "escola crestomática" emanado do círculo de Jeremy Bentham, há dois séculos atrás nas ilhas britânicas (Mesquita, 2009, pp. 329-517). Paul Olson é um dos autores que destaca não apenas o interesse geral da 
burguesia industrial e liberal na Inglaterra do início do século XIX em se servir do método monitorial para promover a instrução básica da população, mas também a natureza capitalista da solução organizativa que então se procurou aplicar para realizar aquele interesse geral (Olson, 2002, p. 158). Noutra perspectiva, Carl Kaestle identifica igualmente uma "continuidade fundamental" entre o sistema lancasteriano e os princípios que estão presentes nos sistemas educativos contemporâneos (Kaestle, 1973, pp. 48-49).

Da mesma forma, o período que ficou conhecido por "social-efficiency age", nos EUA, representa um gigantesco esforço de investigação e experimentação tendo por objectivo a mobilização da ciência para aplicar à educação de massas os métodos próprios da grande produção capitalista (Callahan, 1964; Kliebard, 2004). A envergadura desta tarefa, a grande dimensão da população escolar e a inexistência de meios tecnológicos que permitissem aplicar à "produção de aprendizagens" o princípio da subordinação do trabalhador à máquina existente noutros sectores produtivos, tudo isto impôs, nessas primeiras décadas do século XX, um limite intransponível a qualquer tentativa de capitalização da escolarização de massas. Mas a possibilidade de uma mudança com esse conteúdo foi explicitamente colocada já nessa época (Callahan, op. cit., p. 58), assim como foi também nesse período claramente considerada a condição do aluno como principal produtor na indústria educativa (Bobbitt, 1918, p. 107). Inúmeras investigações e iniciativas foram nesta altura levadas a cabo tendo por propósito principal o incremento da produtividade do trabalho escolar em função dos objectivos educacionais prescritos e com uma preocupação permanente de diminuição de custos e de rentabilidade máxima dos recursos aplicados na educação (vejam-se, por exemplo, os trabalhos de J. F. Bobbitt, W. W. Charters, Leonard Ayres, David Snedden, entre outros). Mas só na época actual, com os avanços entretanto registados nos estudos do currículo, da avaliação das aprendizagens e dos processos cognitivos; com a codificação sistemática das aprendizagens escolares em listas de competências simples e bem especificadas; e com a utilização intensiva das TIC nos processos de aprendizagem e de gestão escolar, só agora aquela preocupação em aumentar a produtividade do trabalho escolar se conjuga com investimentos em larga escala tendo em vista a exploração lucrativa da indústria educativa. 


\section{Sobre o problema da valorização capitalista na indústria educativa}

No actual processo de mudança educativa, a escolarização de massas já não é considerada apenas como um processo diferido da produção e acumulação capitalistas, através da formação da respectiva força de trabalho e da posterior extracção de mais-valia do seu trabalho futuro. Com efeito, na nova organização educativa que agora se configura tenderão a implantar-se processos de valorização capitalista no próprio processo de "produção educativa" e na realização mais ou menos imediata do valor dessa produção. Actualmente, tais processos de valorização assentam sobretudo em contratos celebrados entre as empresas que investem capitais na indústria educativa e as entidades estatais responsáveis pela gestão dos sistemas educativos e das escolas. Mediante tais contratos, as primeiras recebem uma verba estipulada e comprometem-se em troca a prestar determinados serviços e a atingir determinados objectivos, procurando extrair lucros dessa actividade através de uma diminuição dos custos de exploração.

Ora, na actividade educativa a "matéria-prima" que tem de ser trabalhada são pessoas (os alunos) e os trabalhadores dos quais se tem de extrair mais-valia (os professores e outros profissionais do ensino) são compelidos a aferir a sua produtividade através da produtividade do trabalho dos alunos. Tudo na actividade educativa tem agora de ser quantificável e mensurável. Isto implica a redução das aprendizagens a uma lista de competências práticas, a transferência de uma parte significativa do trabalho do professor para o aluno e a mecanização dos processos de aprendizagem e de avaliação. A desumanização da relação educativa que daqui resulta representa uma das principais fontes de resistência à capitalização da actividade educativa ${ }^{5}$.

Por outro lado, a própria realização do "produto" tem também, no caso da educação e da formação, especificidades próprias que dificultam a capitalização desta actividade. De facto, enquanto que em áreas de produção que envolvem o manuseamento de matérias-primas "não-humanas" e em que o suporte final do produto o é também, existe um "produto final" mediante a venda do qual a empresa capitalista se separa definitivamente do mesmo realizando o respectivo valor, no caso da "produção educativa", sendo o consumidor simultaneamente produtor e parte do produto, aquela separação 
pode não acontecer. Assim, se o dito "produto" tiver um escasso valor reprodutivo, como acontece no caso da aquisição de conhecimentos e competências básicas, o ciclo desse produto fica terminado no acto da sua transacção. Mas se esse mesmo produto tiver valor reprodutivo, isto é, se incorpora conhecimentos e competências avançadas, nesse caso o capital persegue o produto, procurando capturar os rendimentos derivados da aplicação desses conhecimentos e competências (Friedman, 2002, pp. 101104; Lleras, 2004).

Apesar da complexidade e da especificidade do processo de valorização capitalista na educação, as políticas educativas actuais procuram forçar a sua realização prática através de uma revolução nos métodos de ensino e aprendizagem e na organização dos sistemas educativos. 0 objectivo é impor na educação de massas relações sociais de produção semelhantes às dos demais sectores produtivos. Assim, a meu ver, é nas categorias marxistas de análise do capitalismo industrial moderno que reside o instrumental teórico mais importante para estudar o actual processo de mudança educativa.

Karl Marx não tratou especificamente do tema da capitalização da actividade educativa, mas considerou implicitamente tal tema quando se referiu à capitalização de outros sectores que têm em comum com essa actividade educativa o facto de se integrarem no que designou por "condições gerais" da produção capitalista. Assim, num texto de 1857/1858 e a propósito da actividade de construção de vias de comunicação, K. Marx analisou as condições de capitalização das actividades ligadas à realização das referidas condições gerais da produção capitalista, afirmando o seguinte:

A assumpção pelo capital (em lugar do governo, que representa a comunidade) da realização de todas as condições gerais de produção pressupõe o máximo desenvolvimento da produção fundada nesse mesmo capital (Marx, 1993, pág. 530/531, sublinhado do autor).

Deste modo, segundo K. Marx, sendo o Estado que nas primeiras fases do desenvolvimento da produção capitalista assegura a realização das respectivas condições gerais, numa fase mais avançada da mesma poderão as actividades ligadas a essa realização ser executadas pelo próprio capital enquanto tal. Reforçando esta ideia, diz Marx que "[o] máximo desenvolvimento do capital existe quando as condições gerais do processo de 
produção social não são financiadas a partir de deduções feitas ao rendimento social, os impostos recolhidos pelo Estado (...), mas são antes financiadas pelo capital enquanto capital" (ibidem, pág. 532), havendo antes enunciado, em referência concreta à construção de vias de comunicação, as condições que propiciam e permitem o investimento capitalista nessa mesma construção, a saber:

Por um lado, a riqueza do país suficientemente concentrada e transformada sob a forma de capital; por outro lado, um volume suficiente de tráfego e o obstáculo representado pela falta de meios de comunicação suficientemente sentido enquanto tal, de forma que o capitalista possa realizar o valor da estrada (em prestações, ao longo do tempo) enquanto estrada (i. e. o seu uso) (ibidem, pág. 530).

Os pressupostos aqui enunciados por K. Marx relacionam-se com a existência de uma concentração de capitais capaz de fazer face a investimentos muito avultados e de retorno lento, com a constituição de uma nova necessidade social que garanta um consumo permanente e massivo do bem respectivo, e, finalmente, com a possibilidade, para o capitalista, de realização do valor desse bem enquanto tal. Sobre esta última condição, acrescenta o seguinte:

Para o capital (...) tomar em mãos a construção da estrada, deve ser pressuposto que não apenas o trabalho necessário mas também o trabalho excedente desenvolvido pelo trabalhador pode ser pago - é este a fonte do seu lucro ( $\mathrm{O}$ capitalista impõe muitas vezes este pagamento através de tarifas proteccionistas, de posições de monopólio ou da acção coerciva do Estado, nas situações em que o indivíduo envolvido na respectiva compra, em condições de livre troca, apenas estaria disposto a pagar quando muito o trabalho necessário (ibidem, pág. 532/533, sublinhado do autor).

Ora, se se aplicarem as três condições atrás referidas ao caso da actividade educativa nos países de capitalismo mais desenvolvido, poder-seá dizer que as duas primeiras (a concentração de riqueza sob a forma de capital e a constituição da educação como necessidade social) se encontram, no fundamental, preenchidas, enquanto que a concretização da terceira condição (a possibilidade de realização do valor produzido) se encontra apenas parcialmente preenchida.

Com efeito, em termos gerais e sobretudo no que diz respeito aos níveis de escolaridade não superior, está-se ainda na fase de o "consumidor" não apenas se limitar a pagar o equivalente a "quando muito (...) o tempo de 
trabalho necessário" (isto é, o estritamente indispensável para a reprodução das condições de produção), como ainda de o fazer por interposta pessoa, ou seja, através de um fundo estatal proveniente dos impostos. Ora, se neste sector se desenvolver (como já sucede e como é provável que continue a suceder) um processo de capitalização da respectiva actividade, a tendência será provavelmente a de o dito "consumidor" passar a pagar directamente "pelo menos" o equivalente ao referido "tempo de trabalho necessário" (sendo a substituição do "trabalho pago" do professor pelo trabalho "não pago" do aluno, ou a substituição do "trabalho vivo" de ambos pelo "trabalho morto" de máquinas, meios indispensáveis para tornar viável, em termos gerais, um tal pagamento), e a de que o pagamento ao capitalista que invista na indústria educativa do lucro equivalente ao "tempo de trabalho excedente" seja feito, no todo ou em parte, com recurso a meios equivalentes aos que Marx, referindose às fontes de lucro capitalista no sector da construção de vias de comunicação, designava (ver citação supra) por "tarifas proteccionistas, situações de monopólio e a acção coerciva do Estado"6.

Marx refere-se em várias passagens das suas obras ao trabalho produtor de mais-valia desenvolvido pelos professores no que designa por "fábricas de educação", propriedade de capitalistas individuais (Marx, 1990, p. $644 ; 1978$, p. 411). Mas, por considerar então o valor dessa produção como insignificante no conjunto da produção capitalista, ele nunca realizou uma análise específica sobre os processos de trabalho e de valorização do capital numa indústria educativa privada com fins lucrativos. Hoje a situação é no entanto bem diferente, sendo as indústrias de alguma forma relacionadas com a educação um dos sectores que atraem capitais em larga escala em busca de aplicações lucrativas. Assim sendo, o desenvolvimento da actual transformação educativa irá progressivamente permitindo e impondo uma investigação sistemática sobre os processos de valorização do capital numa indústria educativa capitalizada. $\mathrm{Na}$ análise dos processos de produção de mais-valia pelos professores, torna-se por sua vez necessário considerar não apenas o seu trabalho directo mas também o trabalho que é transferido destes para os alunos, nos termos anteriormente expostos.

Seja como for, o mencionado processo de capitalização da actividade educativa e, em particular, a possibilidade de realização integral, pelo capital, do valor produzido na mesma, deverá envolver, em princípio, o preenchimento 
de diversos pressupostos gerais, a saber: a constituição geral dos valores produzidos na actividade educativa como valores de troca; o estabelecimento de relações sociais de tipo capitalista no processo de "produção educativa"; a existência de tecnologias com base nas quais seja possível fazer aumentar continuamente a produtividade do trabalho envolvido em tal actividade; e a existência de uma arquitectura legal e jurídica que possibilite e legitime a transacção mercantil dos valores produzidos na actividade em apreço, e que favoreça as possibilidades de acumulação de capital neste sector. Parafraseando ainda K. Marx no texto em referência, pode dizer-se que o grau de realização dos pressupostos atrás enunciados representará "a medida em que às necessidades socialmente estabelecidas do indivíduo (i. e. aquelas que ele sente e cujos bens consome não enquanto ser individual mas em comum com outros - cujo modo de consumo é social pela própria natureza do bem em causa) corresponde não apenas um consumo mas também uma produção que são realizados através da troca mercantil, de um troca individual" (ibidem, p. 532).

\section{Sobre o Estado capitalizador e as formas pró-capitalistas de mercado na transformação educativa}

No quadro do modo de produção capitalista, a questão da viabilidade de uma capitalização global da actividade educativa não está condicionada apenas pela possibilidade "técnica" de efectuar uma exploração lucrativa neste sector, mas depende igualmente de outros factores de natureza económica, política e social, que respeitam às condições de funcionamento da sociedade e do aparelho produtivo em geral e que se podem agrupar no tema da "qualidade educativa".

Desde a sua instituição e dando corpo quer às necessidades do capitalismo quer a reivindicações democráticas das populações, ao "Estado educador" cabia garantir uma formação cívica e profissional que progressivamente se foi estendendo a todos os cidadãos e, também de uma forma progressiva, proporcionar, pelo menos em termos formais, uma igualdade de oportunidades, quer no acesso quer no sucesso educativos. Numa perspectiva de "custos-benefícios", esta situação podia ser vantajosa para o capital, na medida em que permitisse realizar em termos "industriais" e a um preço relativamente barato a formação básica dos cidadãos, 
diminuindo consequentemente o valor da reprodução da força de trabalho da sociedade e socializando os respectivos custos, e na medida ainda em que pudesse proporcionar meios de legitimação e controlo social ao sistema no seu conjunto. Entretanto, o alargamento da escolaridade e a chamada massificação do ensino a todos os níveis, juntamente com os resultados perversos decorrentes da acção dos mecanismos de mercado na actividade educativa (designadamente no âmbito do que é hábito designar por "desvalorização dos diplomas" e da consequente diminuição da qualidade das aprendizagens), vieram pôr em crise a mencionada situação vantajosa em termos de "custos/benefícios", no que respeita à indústria educativa estatal, crise essa que se tornou ainda mais aguda a partir da altura em que se desencadeou um processo de corte geral e sistemático das despesas do Estado com os chamados serviços públicos (Collins, 1979). Em termos económicos clássicos, a indústria educativa estatal "abriu falência" e isso constituiu o sinal que faltava de que tinha "chegado a hora" de capitalizar essa mesma indústria educativa, primeiro submetendo-a a uma disciplina empresarial e, depois, tornando-a numa indústria geradora de lucros. Assim, do ponto de vista das classes dominantes, o problema da "qualidade educativa" devia doravante passar a ser dirimido no quadro de relações económicas abertamente capitalistas nos sistemas educativos (Friedman, op. cit:; 1979).

Sucede que, no quadro estrito da lógica do capitalismo, a qualidade de algo é inerente ao modo da sua produção e circulação até chegar ao utilizador final e é um subproduto do mesmo, ou seja, a qualidade reside mais no processo do que no resultado. Para os defensores do capitalismo educacional é irrelevante a questão de saber se uma escola pública tradicional é "boa" ou "má", constituindo-se como uma verdade axiomática a superior qualidade do "produto" emanado de uma indústria educativa capitalizada e, consequentemente, a inferior qualidade do "produto" de uma indústria educativa estatal ${ }^{8}$. Com efeito, embora o processo de capitalização da actividade educativa comece por aparecer revestido de consignas de "liberdade" e de "democracia" no acesso a um "produto educativo" e a um modo de produção do mesmo que são conhecidos, o objectivo real é a criação de um novo produto e de um novo modo de produção educativa. Nesta perspectiva, os obstáculos hoje existentes à capitalização da actividade 
educativa não se colocam tanto do lado da procura (uma insuficiente "liberdade de escolher"), mas colocam-se antes e sobretudo do lado da oferta (uma ainda incipiente "liberdade de empresa"). Para quê promover a "liberdade de escolha" se não houver depois por onde escolher? As atenções concentram-se assim, por parte dos agentes e partidários da transformação capitalista da actividade educativa, na chamada "investigação e desenvolvimento" (I\&D), com a maior parte das experiências a decorrerem actualmente no âmbito dos sistemas públicos de educação e, dentro destes, nos que albergam os alunos oriundos das classes pobres e trabalhadoras (Whittle, 2005; Hill, 2006; Hess e Finn Jr., 2007; Sandler, 2010).

É no contexto atrás definido que a configuração e o papel do Estado na presente mudança educativa devem ser analisados, nos termos que a seguir se propõem.

Estando em curso um processo de capitalização da actividade educativa com um carácter global e verificando-se uma notável continuidade e coerência nas políticas educativas que o materializam, é possível reconhecer por isso a existência de uma forte e consistente direcção política na presente transformação educativa. Essa direcção política assume formas organizativas diversas e tem o seu locus em diferentes instâncias. Num plano supranacional, este localiza-se em estruturas de governação regional, como a União Europeia, ou em organizações de regulação global, como o Banco Mundial, a OCDE, a Organização Mundial do Comércio e outras (Laval e Weber, 2002; Carnoy, 2000; Robertson, 2006). Num plano nacional, esse locus situa-se nos Estados, nos governos ou em organizações de diverso tipo identificadas com o referido processo.

Todas as linhas de força da actual transformação educativa a que antes se fez referência são assim sistematicamente promovidas e impulsionadas, década após década, governo após governo, quer num plano legal e organizativo quer através da chamada "investigação \& desenvolvimento" nos processos de ensino e aprendizagem. Essa acção sistemática gera nos seus protagonistas um sentimento de "missão" e uma noção de "obra em curso" cada vez melhor definida na sua fisionomia e no seu resultado final (ver, por exemplo, Enlow e Ealy, 2006; Hess, 2008; Sandler, 2010). "Educação, educação, educação", passou a ser um mote recorrentemente usado pelos governos de um grande número de países, 
sendo que, na sua concretização prática, a prioridade educativa vem-se traduzindo invariavelmente, nesses países, em avanços no sentido da empresarialização dos sistemas escolares. Dir-se-ia que passou a existir, nas diversas instâncias de governação global e local, uma espécie de "partido capitalizador" da educação pública, com um programa, uma ideologia, uma estratégia e uma táctica política próprias.

Deste modo, com expressão mais evidente e radical nos países anglosaxónicos, mas um pouco por toda a parte, foi nas últimas décadas desencadeada e promovida uma acção sistemática de destruição das velhas estruturas do "Estado educador" e de construção de novas estruturas políticojurídicas que dêem suporte e garantam a continuidade da transformação educativa em curso $^{9}$. Na verdade, o "partido capitalizador" determina já as políticas públicas de educação em muitos países, em termos tais que se torna possível falar hoje, nesses países, de um "Estado capitalizador" da actividade educativa. Mediante uma intervenção activa por parte das organizações empresariais de cada país ou região e dos interesses capitalistas de algum modo associados à indústria educativa, é no quadro desta entidade que são mobilizados e organizados os apoios políticos, económicos, institucionais, teóricos e intelectuais necessários ao avanço do presente processo de mudança educativa (ver a este propósito, e sobre a realidade dos EUA, Emery e Ohanian, 2004; Bracey, 2003; Poynor e Wolfe, 2005; Coles, 2003).

Neste processo e a partir da acção do "Estado capitalizador", são promovidas e instituídas formas de regulação mercantil da actividade educativa que têm um claro sentido pró-capitalista. $\mathrm{O}$ que melhor define e caracteriza estas formas pró-capitalistas de mercado no interior dos sistemas públicos de educação, parece ser constituído actualmente pelo conjunto de dispositivos e de medidas englobados no objectivo de "melhoria contínua" dos resultados escolares, objectivo esse que, nos termos em que é construído e operacionalizado no quadro do referido "Estado capitalizador", corresponde ao conceito de "melhoria contínua do produto", próprio de uma lógica capitalista de produção, e é, como este, destituído de uma relação directa com a qualidade, em termos de valor de uso, daquilo que é produzido ${ }^{10}$.

Nas relações de trabalho nas escolas, o referido objectivo de "melhoria contínua de resultados" traduz-se na introdução de reformas que façam depender o salário dos professores e a própria manutenção do seu posto de 
trabalho, dos "bons" resultados obtidos pelos alunos (McGuinn, 2010; Corcoran e outros, 2010; Klein, Rhee e outros, 2010). O trabalho do professor passa, nestas condições, a ser pautado pela exigência de fazer trabalhar o aluno até ao limite das suas capacidades (a expressão usada é normalmente a de "desenvolver todo o potencial" do aluno), sendo que este próprio limite está também ele sujeito à regra da "melhoria contínua", num processo que mimetiza o processo clássico de produção capitalista. Isto implica, por exemplo, que um objectivo como é o do "sucesso para todos" os alunos, tenha, no contexto do "Estado capitalizador" da actividade educativa, não mais o significado de um direito, como sucedia (e sucede) no quadro do "Estado educador", mas sim o conteúdo de uma obrigação que, tacitamente e até contratualmente, o aluno (e o professor, para não falar já da família) terá de cumprir em benefício da "empresa educativa", independentemente dos proveitos pessoais que possam advir de tal cumprimento.

Procurando impor, nos termos atrás descritos, uma pressão permanente para a "melhoria contínua" dos resultados escolares, o "Estado capitalizador" promove programas e dispositivos destinados a mobilizar a "iniciativa privada" para apoiar a escola pública na prossecução desse objectivo ${ }^{11}$. A própria natureza deste último opera a selecção da dita "iniciativa privada", marginalizando e tornando crescentemente impraticáveis os projectos com propósitos pedagógicos avançados, e dando antes livre curso às empresas de fabricação de competências e de mecanização do trabalho desenvolvido no meio escolar ${ }^{12}$.

A transição para o capitalismo educacional opera-se assim no interior dos sistemas públicos de escolarização de massas, pretendendo-se que a concessão da gestão desses sistemas a entidades privadas com fins lucrativos mais ou menos assumidos ocorra naturalmente e tendo já instituídas relações de trabalho de tipo capitalista. No caso dos professores, isso vem-se traduzindo em medidas sucessivas de eliminação de direitos adquiridos, de aumento do número de horas de trabalho e do número de alunos a seu cargo, de diminuição dos salários e de desqualificação do trabalho da maioria, ao mesmo tempo que uma minoria é investida em funções de supervisão do trabalho escolar no âmbito de um chamado "novo profissionalismo docente" (Moulthrop e outros, 2006; Stevenson, 2007). Assim e no conjunto do processo de trabalho nas escolas, está-se presentemente 
numa fase que tem semelhanças com o que $\mathrm{K}$. Marx, referindo-se aos primórdios da produção capitalista, designou de "produção de mais-valia absoluta". Esta fase antecede o que se pretende que seja uma revolução na indústria educativa, assente na produção de "mais-valia relativa" e da consequente procura de imposição de métodos de produção e de relações sociais abertamente capitalistas (Marx, 1990, 643-654). Se isto vier a ocorrer como é provável, e à medida que tal for acontecendo, será possível estudar e compreender melhor o processo de valorização do capital numa indústria educativa capitalizada. Da mesma forma, à medida que se desenvolvam, como vem acontecendo, inevitáveis movimentos sociais de resistência a uma tal transformação, será possível debater com melhor fundamento o sentido e o significado das necessárias alternativas à mesma.

\section{Notas}

1 "A Edison não foi apenas uma experiência na privatização da escola pública mas foi sim a experiência das sociedades empresariais para tomarem o controlo das escolas públicas e geri-las com fins lucrativos". (Saltman, p. 3).

2 Quatro áreas de negócio principais são incluídas no que esta investigadora designa por "nova privatização da educação": "desenvolvimento e preparação de testes e exames, gestão e análise de dados, explicações e tutoria, e programação de conteúdos de aprendizagem" (Burch, 2006, p. 2589).

$3 \mathrm{Na}$ maior parte dos casos, as análises contemporâneas sobre o processo de trabalho nas escolas assentam numa concepção da "produção educativa" como não podendo ser mais do que um processo de formação da força de trabalho futura, e quase sempre se têm limitado apenas a uma das componentes do trabalho escolar, o trabalho dos professores. Ver a este propósito os trabalhos de Michael Apple, Martin Lawn, Jenny Ozga, Susan Robertson, Alan Reid, Ken Harris, John Smith, entre outros. Fora da corrente anglo-saxónica, este campo de análise foi explorado e desenvolvido em diversos outros contextos. Destes, merece destaque a corrente de investigação sobre trabalho e educação que, sobretudo a partir dos anos 1980, teve um importante desenvolvimento no Brasil, a qual, a nosso ver, não logra ultrapassar as limitações antes mencionadas. Ver, a propósito, os trabalhos de Álvaro Moreira Hypólito, Dermeval Saviani, Nicanor Palhares Sá, Hormindo de Souza Júnior, Ramon de Oliveira, entre outros.

4 Existe hoje uma vasta produção teórica sobre a privatização ou a empresarialização dos sistemas educativos, atribuindo estas dinâmicas a causas político-ideológicas, culturais ou económicas que influenciam a organização desses sistemas. As transformações educativas são assim integradas em correntes gerais de mudança que afectam o funcionamento dos Estados e dos serviços públicos, chamadas, por exemplo, de pós-mordenismo, neoliberalismo ou novo gerencialismo. Noutros 
casos elas são apresentadas como sendo uma resposta a alterações nos sistemas de produção económica, estas designadas de pós-fordismo, economia do conhecimento, capitalismo cognitivo, etc. Noutros casos ainda as mudanças educativas são perspectivadas como uma adaptação do trabalho escolar a novos contextos económicos, sociais e tecnológicos, originando um chamado "novo profissionalismo docente" que coexiste com a parcelização e desqualificação de outras funções nesse mesmo trabalho escolar.

5 A máxima de Jeremy Bentham, referindo-se à situação das crianças nas escolas monitoriais do início do século XIX em Inglaterra ("Chamem-Ihes soldados, chamem-lhes monges, chamem-lhes máquinas - desde que sejam felizes, isso não me preocupa." - Bentham, 1843, p. 64), mantém hoje uma forte actualidade. Ver a este propósito e como exemplo o confronto de posições entre um forte crítico da empresarialização das escolas frequentadas sobretudo pelas crianças das populações afro-americanas nos EUA, Jonathan Kozol, e um destacado promotor actual da "gestão científica" nos processos de ensino/aprendizagem, Robert Slavin (Kozol, 2005, pp. 65-74; Slavin, 2005).

6 No seu texto "The Role of Government in Education", M. Friedman formula já explicitamente o propósito de que os "consumidores" paguem o "serviço educativo" que utilizam, embora reconheça a dificuldade de concretizar tal objectivo e proponha em consequência, como solução intermédia e temporária, uma solução já avançada no século XIX por John Stuart Mill: o financiamento estatal directo às famílias, o cheque-ensino (ver Milton Friedman, op. cit., pp. 87-93). Outros autores igualmente partidários do capitalismo educacional sugerem a criação de mecanismos mistos, em que as famílias suportem integral ou parcialmente os custos com a educação, sendo instituídos mecanismos de créditos fiscais ou de filantropia para apoiar as famílias carenciadas (ver, por exemplo, Coulson, 2006, pp. 117-118). A aplicação do princípio do "utilizador-pagador" é assim hoje proposta nos círculos dominantes também para a escolaridade obrigatória. Ao lado deste princípio e com a mesma origem, surge normalmente a consideração de que os investimentos capitalistas privados na educação correspondem à prestação de um "serviço público", devendo estes ser por isso protegidos e subvencionados com dinheiros públicos.

7 "Numa perspectiva liberal de mercado, é irrelevante saber se uma escola pública é 'boa' ou 'má'. O modelo T [da Ford] foi um grande sucesso, mas ele era parte de um sistema no qual os produtores têm de melhorar continuamente os seus produtos se quiserem sobreviver." (Lieberman, 2006, p. 99) ; "Algumas escolas são melhores que outras mas (...) muito poucas chegam a ser adequadas, e muito menos próximas daquilo que poderiam ser tendo em conta o dinheiro que gastam. Enquanto não fizermos explodir o mito de que a maioria das escolas estão bem (...) muitas pessoas votarão contra mudanças que possam afectar a sua escola, o que significa que se oporão a reformas que signifiquem uma mudança sistémica genuína." (Merrifield, 2006, p. 134).

8 "O cheque-ensino é um meio, não é um fim [;] o seu propósito é proporcionar aos pais liberdade de escolha, sendo que a livre escolha dos pais se destina a promover a competição e permitir assim à indústria educativa deixar de funcionar como o fazia no século XVII e passar a ter um modo de funcionamento próprio do século XXI, com mais inovação e desenvolvimento. Não há qualquer razão para que não exista 
na produção educativa o mesmo tipo de mudanças que ocorreram na produção de computadores, de televisores ou de outras coisas similares." (Friedman, 2003)

9 Defensor da capitalização da actividade educativa, Guilbert C. Hentschke é um dos autores que se refere a uma dualidade na acção das estruturas estatais relativamente à educação pública, demarcando-se neste aspecto de M. Friedman nos termos seguintes: "A referência de Friedman ao governo como sendo 'o Estado', se bem que tecnicamente correcta então como agora, encobre a natureza crescentemente competitiva de jurisdições governamentais distintas." Reconhecendo que "os governos vão aceitando e promovendo cada vez mais a criação de alternativas à educação fornecida pelo Estado", este autor enfatiza a importância da supervisão por órgãos estatais do processo de transformação educativa, afirmando a propósito de iniciativas relacionadas com o cheque-ensino, o seguinte: "[O] incremento da supervisão estatal sobre o funcionamento das escolas é tão importante para as iniciativas de cheque-ensino como o é o declínio da hegemonia das escolas públicas." (Hentschke, 2006, pp. 16-18). Ver também a este propósito os detalhados conselhos de táctica política que outro defensor do capitalismo educacional, John Merrifield, elabora para uso do "partido capitalizador" e das ramificações deste no interior das estruturas de governação da educação pública nos EUA (Merrifield, 2006).

10 Num dos muitos documentos emanados de organizações empresariais directamente empenhadas nas presentes transformações educativas nos EUA, a procura de "melhoria contínua" do "produto educativo" é explicitamente comparada à que se verifica noutros sectores produtivos, nos termos seguintes: "A procura dos consumidores está continuamente a desafiar as empresas a melhorar continuamente os seus produtos e serviços. Agora, vimos desafiar os parceiros educativos - professores, administradores eleitos, pais e alunos - para que se juntem a nós de modo a que, trabalhando em conjunto, possamos ajudar todos os alunos a atingir os mais elevados níveis." (The Business Coalition for Educational Excellence at the New Jersey Chamber of Commerce, 2001).

11 No caso dos EUA, esta mobilização da iniciativa privada pelas entidades responsáveis pela educação pública conheceu impulsos importantes, primeiro durante toda a década de 1990 no seguimento da aprovação do programa federal "America 2000" (2000) e da legislação inserida no "Goals 2000, Educate America Act" (1994); depois, durante a década de 2000 no âmbito do "No Child Left Behind Act" (2001); e, no momento actual, com o conjunto de programas e medidas inseridos na iniciativa federal "Race to the Top". Paralelamente a estes programas estatais e em estreita articulação com os mesmos e respectivos objectivos, desenvolvem-se igualmente múltiplas iniciativas englobadas no conceito de filantropia (ver a este propósito Hess, 2005).

12 Existe hoje nos EUA uma abundante literatura que expõe e denuncia a forma como empresas e programas que se propõem garantir o "sucesso" de todos os alunos nas aprendizagens básicas operam realmente com uma notória indiferença pela qualidade humana da relação educativa. Ver a este propósito Kozol, 2005; Garan, 2004; Altwerger, 2005; Khon e Shannon, 2002. 


\section{Referências}

Altwerger, B. (ed.) (2005). Reading for profit - How the bottom line leaves kids behind. Portsmouth, $\mathrm{NH}$ : Heinemann.

Bentham, J. (1843). Letter XXI: Schools. In John Bowring (ed.), The Works of Jeremy Bentham, Volume 4. Edimburgo: William Tait. (http://oll.libertyfund.org , acedido em 1 de Março de 2008)

Bentham , J. (2005). Chrestomathia: Being a Collection of Papers Explanatory of the Design of an Institution, Proposed to Be Set on Foot Under the Name of the Chrestomathic Day School, or Chrestomathic School, for the Extension of the New System of Instruction to the Higher Branches of Learning, for the Use of the Middling and Higher Ranks in Life, in John Bowring (ed.), The Works of Jeremy Bentham, Volume 8, pp. 1-191. London: Elibron Classics.

Bobbitt, J. F. (1918). The curriculum. Boston: Houghton Mifflin Company.

Bracey, G. W. (2003). What You Should Know About the War Against America's Public Schools. Boston: Pearson Education, Inc.

Burch, P. E. (2006). The New Educational Privatization: Educational Contracting and High Stakes Accountability, Teachers College Record 108, no. 12: 2582-2610

Callahan, R. E. (1964). Education and the cult of efficiency - A study of the social forces that have shaped the administration of the public schools. Chicago e Londres: The University of Chicago Press.

Carnoy, M. (2000). Globalization and educational reform. In Nelly P. Stromquist and Karen Monkman (eds.), Globalization and education - Integration and contestation across cultures, pp. 43-61. Boston: Rowman \& Littlefield Publishers, Inc.

Christensen, C. M., Horn, M. B. e Johnson, C. W. (2008). Disrupting class - How disruptive innovation will change the way the world learns (Nova lorque: McGraw-Hill.

Coles, G. (2003). Reading the naked truth - Literacy, legislation, and lies. Portsmouth, $\mathrm{NH}$ : Heinemann.

Collins, R. (1979). The credential society: Historical sociology of education and stratification. Nova lorque: Academic Press.

Corcoran, S. P. e outros (2010). Can teachers be evaluated by their students test scores? Should they be? The use of value-added measures of teacher efectiveness in policy and practice. Nova lorque: Annenberg Institute of School Reform at Brown University. (http://www.annenberginstitute.org, acedido em 12 de Dezembro de 2010).

Coulson, A. (2006). A Critique of pure Friedman: An empirical reassessment of 'The Role of Government in Education'. In Robert C. Enlow and Lenore T. Ealy (eds.), Liberty \& Learning - Milton Friedman's Voucher Idea at Fifty. Washington, D.C.: Cato Institute.

Emery, K. e Ohanian, S. (2004). Why Is Corporate America Bashing Our Public Schools? Portsmouth, $\mathrm{NH}$ : Heinemann. 
Enlow, R. C. \& Ealy, L. T. (eds.) (2006). Liberty \& Learning - Milton Friedman's Voucher Idea at Fifty. Washington D.C.: Cato Institute.

Friedman, M. (2002), The role of government in education. In M. Friedman, Capitalism and freedom, pp. 85-107. Chicago e Londres: The University of Chicago Press.

Friedman , M \& Friedman, R. (1980). What's wrong with our schools?. In Milton Friedman \& Rose Friedman, Free to choose, pp. 150-188. Londres: Secker \& Warburg.

Friedman , M. (2003). Friedman on School Vouchers - Milton Friedman Interview on CNBC. 24 de Março de 2003. (http://www.friedmanfoundation.org/news/ 200303-24.html, acedido em 23 de Agosto de 2006).

Garan, E. M. (2004). In defense of our children - When politics, profit, and education collide. Portsmouth, $\mathrm{NH}$ : Heinemann.

Heilbroner, R. L. (1986). The nature and logic of capitalism. New York \& London: W. W. Norton \& Company.

Hentschke, G. e outros (2002). Education Management Organizations: Growing a Forprofit Education Industry with Choice, Competition and Innovation, Policy Brief 21, Reason Public Policy Institute. (http://www.reason.org/pb21.pdf, acedido em 22 de Maio de 2007).

Hentschke, G. C. (2006). The role of government in education: Enduring principles, new circumstances, and the question of 'shelf life'. In R. C. Enlowt \& L. T. Ealy (eds.), Liberty \& learning - Milton Friedman's voucher idea at fifty, pp. 11-23. Washington D.C.: Cato Institute.

Hess, F. M. (ed.) (2005). With the best of intentions - How philanthropy is reshaping K12 education. Cambridge, Massachusetts: Harvard Education Press.

Hess, F. M. e Finn Jr., Chester E. (2007). What innovators can, and cannot, do. Education Next, n. 2, 2007. Hoover Institution. (http://www.hoover.org/ publications/ednext/6022146.html, acedido em 21 de Março de 2007)

Hess, F. M. (ed.) (2008). The future of educational entrepreneurship - Possibilities for school reform. Cambridge, Massachusetts: Harvard Education Press.

Hill, P. T. (2006). Put learning first - A portfolio approach to public schools. Policy Report. Progressive Policy Institute, February 2006.

Horn, M. B. e Staker, H. (2011). The Rise of K-12 Blended Learning. Innosight Institute, Inc. (http://www.innosightinstitute.org, acedido em 2 de Fevereiro de 2011).

Kaestle, Carl F. (1973). Introduction, in Carl F. Kaestle (ed.), Joseph Lancaster and the monitorial school movement - A documentary history, pp. 1-49. Nova lorque e Londres: Teachers College Press.

Klein, J., Rhee, M. and others (2010). How to Fix Our Schools: A Manifesto by Joel Klein, Michelle Rhee and Other Education Leaders. The Washington Post, October 10, 2010, B01, http://www.washingtonpost.com/wp-dyn/content/ article/2010/10/07/AR2010100705078_pf.html, acedido em 19 de Novembro de 2010).

Kliebard, H. M. (2004). The Struggle for the American Curriculum, 1893-1958. Nova lorque e Londres: Routledge Falmer.

Kohn, A. e Shannon, P. (eds.) (2002). Education, Inc. - Turning learning into a business. Portsmouth, $\mathrm{NH}$ : Heinemann. 
Kozol, J. (2005). The Shame of the Nation - The Restoration of Apartheid Schooling in America. Nova lorque: Three Rivers Press.

Lancaster, J. (1805). Improvements in education as it respects the industrious classes of the community, containing, among other important particulars, an account of the institution for the education of one thousand children, Borough Road Southwark; and of the new system of education on which it is conducted. Londres: Darton and Harvey.

Lancaster, J. (1821). The Lancasterian System of Education, with Improvements. Baltimore: W. M. Ogden Niles.

Laval, C. e Weber, L. (eds.) (2002). Le Nouvel ordre éducatif mondial - OMC, Banque Mondiale, OCDE, Comission Européenne. Paris : Éditions Nouveaux Regards.

Lieberman, M. (2006). Free-Market Strategy and Tactics in K-12 Education. In R. C. Enlow e L. T. Ealy (eds.), Liberty \& Learning - Milton Friedman's Voucher Idea at Fifty, pp. 81-101. Washington D.C.: Cato Institute.

Lleras, M. P. (2004). Investing in human capital - A capital markets approach to student funding. Cambridge: Cambridge University Press.

Marx, K. (1978). Theories of Surplus-Value, Part I. Moscovo: Progress Publishers.

Marx, K. (1990). Capital - A Critique of Political Economy, v. I. Penguin Books.

Marx, K. (1993). Grundrisse - Foundations of the critique of political economy. Londres: Penguin Books.

McGuinn, P. (2006). The Policy Landscape, in Frederick Hess (ed.), Educational Entrepreneurship: Realities, Challenges, Possibilities, pp. 63-81. Cambridge, Massachusetts: Harvard Education Press.

McGuinn, P. (2010). Ringing the bell for K-12 teacher tenure reform. Washington, D. C.: Center for American Progress. (http://www.americanprogress.org, acedido em 10 de Dezembro de 2010).

Merrified, John (2006). Discipline is the Key to Milton Friedman's Gold Standard for Education Reform. In R. C. Enlow e L. T. Ealy (eds.), Liberty \& Learning - Milton Friedman's Voucher Idea at Fifty, pp. 125-137. Washington D.C.: Cato Institute.

Mesquita, L. (2009a). A Relação entre a educação e o trabalho no contexto do actual processo de capitalização da actividade educativa, Trabalho \& Educação, v. 18, n. 2, Maio-Agosto de 2009, 171-91.

Mesquita, L. (2009b). A capitalização da actividade educativa nos níveis básico e secundário de escolaridade - $O$ caso da instrução das crianças pobres e trabalhadoras em Inglaterra, entre o século XVII e o primeiro quartel do século $X I X$. Tese de Doutoramento aprovada em Novembro de 2009 na Faculdade de Psicologia e de Ciências da Educação da Universidade do Porto.

Meyer, R. J. (2005). Invisible teacher/invisible children: The company line. In B. Altwerger (ed.), Reading for profit - How the bottom line leaves kids behind, pp. 96-111. Portsmouth, NH: Heinemann.

Molnar, A. (2006). For-profit K-12 Education: Through the Glass Darkly. In F. M. Hess (ed.), Educational Entrepreneurship: Realities, Challenges, Possibilities, (pp. 103-123). Cambridge, Massachusetts: Harvard Education Press. 
Molnar, A., Miron, G. e Urschel, J. L. (2010). Profiles of For-Profit Education Management Organizations: Twelfth Annual Report - 2009-2010. Boulder, CO: National Education Policy Center.

Mosher, F., Fuhrman, S. H. \& Cohen, D. K. (2007). The research that policy needs. Educational Horizons, 86(1), 19-28. (http://www.pilambda.org/ horizons/v861/mosher.pdf, acedido em 1 de Janeiro de 2008).

Moulthrop, D. e outros (2006). Teachers have it easy - The big sacrifices and small salaries of America's teachers. Nova lorque e Londres: The New Press.

Olson, P. A. (2002). The Kingdom of Science: Literary Utopianism and British Education, 1612-1870. Lincoln: University of Nebraska Press.

Poynor, L. e Wolfe, P. M. (eds.) (2005). Marketing fear in America's public schools - The real war on literacy. Nova Jersey e Londres: Lawrence Erlbaum Associates, Publishers.

Robertson, S. (2006). Globalisation, GATS and trading in education services. In J. Kall and R. Rinne (eds.), Supranational Regimes and National Education Policies Encountering Challenge. Helsinki: Finnish Education Research Association (http://www.bris.ac.uk/education/people/academicStaff/eds/r/ publications, acedido em 10 de Dezembro de 2010).

Robertson, S. (2007). Public-Private Partnerships, digital firms, and the production of a neo-liberal education space at the European scale. In K. N. Gulson and C. Symes (eds.), Spatial Theories of Education - Policy and Geography Matters, (pp. 215-231). Londres e Nova lorque: Routledge.

Saltman, K. J. (2005). The Edison Schools-Corporate Schooling and the Assault on Public Education. Nova lorque e Londres: Routledge.

Sandler, M. R. (2010). Social Entrepreneurship in Education - Private Ventures for the Public Good. Lanham: Rowman \& Littlefield Education.

Slavin, R. E. (2005). Shame Inded. Whitney Tilson's School Reform Blog, (http://edreform.blogspot.com/2006/04/shame-indeed-sucess-for-allrebuts.html, acedido em 15/07/2007)

Stevenson, H. (2007). Restructuring teacher's work and trade union responses in England: Bargaining for change? American Educational Research Journal, v. 44, n. 2, 224-51, June 2007.

Subotnik, R. F. e Walberg, H. J., eds. (2006). The scientific basis of educational productivity. Greenwich, Connecticut: Information Age Publishing.

The Business Coalition for Educational Excellence at the new Jersey Chamber of Commerce (2001). Getting down to the business of learning - A position paper. Nova Jersey: New Jersey Chamber of Commerce. (http://www.bcee.org, acedido em 22 de Abril de 2007).

Thernstrom, A. e Thernstrom, S. (2004). No Excuses - Closing the Racial Gap in Learning. Nova lorque: Simon \& Schuster Paperbacks.

Whittle, C. (2005). Crash Course - Imagining a Better Future for Public Education. Nova lorque: Riverhead Books.

Wicks, M. (2010). A National Primer on K-12 Online Learning, Version 2. International Association for K-12 Online Learning. (http://www.inacol.org/ research/docs/iNCL_NationalPrimerv22010-web.pdf, acedido em 2 de Fevereiro de 2011). 
30| Leopoldo Mesquita

PROLEGOMENA ON THE PROCESS OF CAPITALIST TRANSFORMATION OF EDUCATIONAL ACTIVITY AT THE ELEMENTARY AND SECONDARY SCHOOLING

\section{Abstract}

This paper aims to expose the foundations of a suggested new field on educational research, whose object is the capitalist transformation (or capitalization) of the educational activity in the elementary and secondary levels, which is considered as the present dominant trend in educational policies all over the world. It is argued that such an educational change configures a classic process of capitalist transition whose nodal point is the transformation of school work. Under the slogan of "continuous improvement" of school results, it is intended to constitute the productivity of students work as the measure of the productivity of the teacher's work. In this context, a detailed study of the forms of capital valorization in the education industry is required. Occurring mainly within the public education systems, the current educational transformation involves deep changes both in state structures and in the relationships of educational production. The concepts of capitalizer state and for-capitalist forms of market are used to analyze these changes.

Keywords

Capitalization of education systems; School work; Capitalizer state

PROLÉGOMÈNES SUR LE PROCÈS DE TRANSFORMATION CAPITALISTE DE L'ACTIVITÉ ÉDUCATIVE AUX NIVEAUX ÉLÉMENTAIRE ET SÉCONDAIRE DE SCOLARITÉ

Résumé

Ce texte vise à présenter les fondements de ce qui est considéré comme un nouveau champ de recherche en éducation, dont l'objet est la transformation capitaliste (ou capitalisation) de l'activité éducative dans l'enseignement 
élémentaire et secondaire, considérée ici comme la tendance qui prévaut actuellement dans les politiques éducatives au niveau mondial. II est soutenu que ce changement éducatif représente un processus classique de transition capitaliste dont le point nodal est la transformation du travail au milieu scolaire. Sous le slogan de «amélioration continue» des résultats scolaires, on prétend que la productivité du travail de l'enseignant soit mesurée par la productivité du travail des élèves. Une telle situation rend nécessaire une étude approfondie des formes de valorisation du capital investi dans l'industrie éducative. Survenant principalement au sein des systèmes publics d'éducation, la présente transformation implique des changements profonds dans les structures étatiques et dans les relations de production éducative. Les concepts d'État capitalisateur et de formes pro-capitalistes de marché sont utilisés pour examiner cette transformation.

Mots-clé

Capitalisation des systèmes d'éducation; Travail scolaire; État capitalisateur

Recebido em Agosto, 2010 Aceite para publicação em Maio, 2011 